\title{
Knowledge and self-care practice of leprosy patients at ALERT Hospital, Ethiopia
}

\author{
LISANAWORK GIRMA*, KIDIST BOBOSHA**, \\ TSEGAYE HAILU** \& EDESSA NEGERA*** \\ *All African Leprosy, Tuberculosis Rehabilitation and Training \\ Centre (ALERT), Addis Ababa, Ethiopia \\ **Armauer Hansen Research Institute (AHRI), Addis Ababa, \\ Ethiopia \\ ***London School of Hygiene and Tropical Medicine, UK
}

Accepted for publication 4 December 2018

\begin{abstract}
Summary
Introduction: In addition to multi-drug treatment, patient self-care practice is crucial for the successful treatment of the disease. This study assessed the knowledge and self-care practices of leprosy patients at ALERT leprosy referral hospital in Ethiopia.

Methods: A total of 424 leprosy patients were interviewed using pre-tested structured questionnaires. The questionnaires included core points such as sociodemographic characteristics, knowledge of leprosy and self-care practices. Bloom's cut off point was used to describe the knowledge and self-care practices of the respondents and statistical significance was assessed at $95 \%$ confidence interval with $5 \%$ of level of significance.

Results: The knowledge score of the respondents was poor for $276(65.1 \%)$ and good for $148(34.9 \%)$. The level of knowledge varied significantly with respect to age group ( $\mathrm{p}<0.01)$, sex $(\mathrm{p}<0.01)$, marital status $(\mathrm{p}=0.003)$, educational status $(\mathrm{p}<$ $0.01)$ and income $(p<0.01)$. About $77.4 \%$ of interviewed patients had poor self-care practices and only 22.6 of patients had a good self-care practice score $(\mathrm{p}<0.01)$. Age $(\mathrm{p}=0.002)$, previous disability due to leprosy $(\mathrm{p}<0.01)$, knowledge of leprosy $(\mathrm{p}=0.038)$ and income $(\mathrm{P}=0.028)$, were significantly associated with poor selfcare practice.

Conclusion: Although leprosy treatment, disability prevention and rehabilitation programs have been run in the country for decades, poor leprosy self-care practice and poor leprosy knowledge has been confirmed in this study. Therefore, the leprosy program should re-visit its strategy and mode of delivery to improve the leprosy knowledge and leprosy self-care practices of patients.
\end{abstract}

Correspondence to: Edessa Negera (e-mail: edessan@yahoo.com) 


\section{Introduction}

According to the World Health Organization (WHO), the prevalence rate of leprosy has been reduced by $90 \%$ from $21 \cdot 1$ per 10,000 in 1985 to less than 1 per 10,000 by $2000 .{ }^{1}$ The prevalence of leprosy has decreased by $97 \%$ in the past 3 decades, dropping from $5 \cdot 2$ million in 1985 to 171,948 in $2017 .{ }^{2}$ On the other hand, new case detection has dropped by less than $10 \%$ in a decade. In 2007, a total of 258,133 new cases were reported to WHO, while 214,783 new cases were reported in $2017 .^{2}$ New cases with grade- 2 disability (G2D) have only reduced from 14,403 cases in 2007 to 12,819 cases in $2017,{ }^{2}$ which underlines the ineffectiveness of the current leprosy control strategy. Although the prevalence of leprosy is declining, the stagnant level of new case detection, leprosy induced disabilities, social discrimination and stigma continue to be an important global challenge. , $^{3,4}$

Ethiopia is one of the 122 leprosy endemic countries. The registered prevalence of leprosy in Ethiopia has been reduced from 5,371 cases in 2007 to 3,692 cases in 2017, a reduction of about $35 \%$ in 10 years. $^{2}$ On the other hand, new case detection reduced from 4,187 cases to 3,692 over the same period - a reduction of only $6 \%$ in ten years. In contrast, the number of new patients with G2D increased from 411 cases in 2007 to 419 cases in $2017 .^{2}$ Over the past ten years, the proportion of children with grade 2-disabilitties reported in Ethiopia has been about 10\%. Among the 419 new cases with grade2-disabilities reported in Ethiopia in 2017, 39 of them were children. ${ }^{2}$ The high proportion of children with grade 2-disabilities in Ethiopia indicates the presence of active transmission and the late diagnosis of the disease.

In Ethiopia, the integration of leprosy into the general health program has created both challenges and opportunities for effective management of persons affected by leprosy, particularly those with disability. ${ }^{5}$ It is an opportunity because of the improved access to health services by those in need, which was not possible with a vertical set up. The challenge is that integration means that patients are seen by general health workers during outpatient visits who do not have adequate training in leprosy, possibly leading to misdiagnosis and late treatment. ${ }^{6}$ Misdiagnosis and late retreatment are one of the main causes of disability in leprosy patients. Previous work has shown that among 601 general health workers from 300 health centres and 52 general hospitals in Ethiopia, only $18 \%$ could correctly diagnose and treat leprosy patients at the general public health facilities. ${ }^{5}$ Integration of leprosy into the general health program therefore requires significant capacity building to enable accurate diagnosis and timely treatment of patients.

With the fall in the number of new cases, there is an increasing shift in focus to prevention of disability. ${ }^{7}$ Self-care practice in leprosy is a professionally supported set of practices by leprosy patients to improve and restore health and self-esteem. ${ }^{4,8}$ It is a daily activity that is initiated and maintained by the person affected, needing his/her active engagement. Hence, self-care is a process that permeates life and is therefore self-motivated and essentially depends on the commitment of the individual. ${ }^{7}$ Proper self-care practice helps to reduce leprosy induced disability and stigma. However, the knowledge and perception of leprosy patients could affect the outcome of self-care practice. ${ }^{9,10}$ Therefore, understanding the knowledge and perception of leprosy patients towards leprosy self-care practice is critical to developing a meaningful leprosy control and rehabilitation program in the country. ${ }^{11}$ This study was initiated to investigate the knowledge and perception of leprosy patients towards self-care practice at ALERT Hospital, Ethiopia. 


\section{Materials and Methods}

STUDY DESIGN

A cross sectional study was conducted using quantitative methods. The study was done within the framework of the leprosy self-care and rehabilitation program at ALERT Hospital.

Source of samples and sampling method: Study subjects were recruited from among leprosy outpatients attending various departments: physiotherapy, medical clinics, orthopaedic workshop and the ulcer clinic. Patients registered as leprosy cases at least 2 months previously were eligible. Leprosy patients below 15 years of age and those who did not give their consent were excluded from the study. A systematic random sampling method was used to enrol subjects. A total of 424 leprosy patients were enrolled.

Data collection: Data were collected using a structured questionnaire, through face to face interviews. Core points included demographic data, early signs and symptoms of leprosy, cause and treatment of leprosy, infectivity, curability and deformity of leprosy. Self-care questions such as wound soaking, paraffin lubricant application to the wound, trimming of the wound edge, wound dressing and regular wound cleaning were also included. Questions about the importance of self-care practices such as soaking, wound trimming and wound cleaning were included. The questionnaire was first prepared in English and then translated into Amharic; it was administered by eight trained data collectors. Data collectors and 2 supervisors were trained for one day to create a common understanding on each question. Following the training, a pilot test was conducted to validate the tool.

\section{OPERATIONAL DEFINITIONS}

We used Bloom's cut off point to measure the knowledge and self-care practice of the respondents. ${ }^{12}$ The percentage of correct responses to a set of 15 knowledge questions and 15 self-care practice questions was used to grade knowledge and self-care practices, as follow:

Poor knowledge: Participants who answered "yes" to $59 \%$ or below $(\leq 8 / 15)$ of the knowledge and perception questions were considered to have a poor knowledge of leprosy.

Good Knowledge: Participants who answered "yes" to above $59 \%(>8 / 15)$ of the knowledge and perception questions were considered to have a good knowledge of leprosy.

Poor self-care practice: Participants who answered "yes" to $59 \%$ or below $(\leq 8 / 15)$ of the self-care practice questions were considered to have poor self-care practice.

Good self-care practice: Participants who answered "yes" to above $59 \%(>8 / 15)$ of the self-practice questions were considered to have good self-care practice.

\section{STATISTICAL ANALYSIS}

The anonymous demographic and clinical data were entered into an Excel database and analysed using SPSS 23 version-1 statistical software. Chi-square test was used test the level of significance of each variable at $\alpha=5 \%$ with $95 \%$ confidence interval. Parametric methods were used to analyse numerical variables and the mean was used for reporting for these variables whenever required. 


\section{ETHICAL CONSIDERATIONS}

The protocol was approved by the AHRI/ALERT Ethical Review Committee with approval number of P019/16. The information sheet was read to the participants. A support letter was obtained from the ALERT Hospital. Written consent was obtained from each of the participants, as recommended by the ethical review committee. Parental assent was obtained for study participants of age 15-17 years. Children under 15 years were excluded from the study. All personal information was kept confidential and reporting was made anonymous.

\section{Results}

\section{SOCIO-DEMOGRAPHIC CHARACTERISTICS OF STUDY SUBJECTS}

A total of 424 leprosy patients were recruited to the study. The median age of the respondents was 48 years (range: $15-85$ years). Among the respondents 236 (55.7\%) were male. About half of the participants, $226(53.3 \%)$, were married. Considering their employment status 387 $(91.3 \%)$ were employed, although a majority (89.8\%) earned less than $1000 \mathrm{ETB} / \mathrm{month}$ which is about $\$ 1 /$ day (Table 1 ).

Table 1. Socio demographic characteristics of the respondents at enrolment

\begin{tabular}{|c|c|c|}
\hline Characteristics (Variables) & Number $(\mathrm{N})$ & Percent $(\%)$ \\
\hline \multicolumn{3}{|l|}{ Age (years) } \\
\hline $14-23$ & 40 & $9 \cdot 4$ \\
\hline $24-33$ & 49 & $11 \cdot 6$ \\
\hline $34-43$ & 67 & $15 \cdot 8$ \\
\hline $44-53$ & 98 & $23 \cdot 1$ \\
\hline$>53$ & 170 & $40 \cdot 1$ \\
\hline \multicolumn{3}{|l|}{ Gender } \\
\hline Male & 236 & $55 \cdot 7$ \\
\hline Female & 188 & $44 \cdot 3$ \\
\hline \multicolumn{3}{|l|}{ Marital status } \\
\hline Single & 99 & $23 \cdot 3$ \\
\hline Married & 226 & $53 \cdot 3$ \\
\hline Divorced & 52 & $12 \cdot 3$ \\
\hline Separated & 9 & $2 \cdot 1$ \\
\hline Widowed & 38 & $9 \cdot 0$ \\
\hline \multicolumn{3}{|l|}{ Occupational status } \\
\hline Employed & 387 & $91 \cdot 3$ \\
\hline Unemployed & 37 & 8.7 \\
\hline \multicolumn{3}{|l|}{ Educational status } \\
\hline Illiterate & 178 & 42 \\
\hline Read and write & 58 & $13 \cdot 7$ \\
\hline Primary & 94 & $22 \cdot 2$ \\
\hline Secondary and above & 94 & $22 \cdot 2$ \\
\hline \multicolumn{3}{|l|}{ Income $(\mathrm{ETB}) *$} \\
\hline $0-150$ & 116 & $27 \cdot 4$ \\
\hline $151-450$ & 109 & $25 \cdot 7$ \\
\hline $451-600$ & 73 & $17 \cdot 2$ \\
\hline $601-1000$ & 80 & $18 \cdot 9$ \\
\hline$>1000$ & 46 & $10 \cdot 8$ \\
\hline
\end{tabular}

$* \mathrm{ETB}=$ Ethiopian Birr; Total sample size $=424$ respondents. 
SELF-CARE PRACTICE OF LEPROSY PATIENTS, ALERT HOSPITAL

Among the 424 respondents, only $43(10 \cdot 1 \%)$ use paraffin wax for lubricating the wound, as prescribed by the leprosy care professionals. About one in four patients practice trimming of the wound and only one in ten patients cleans the wound. Among the respondents, more than $80 \%$ of them do not believe in the importance of wound soaking. On the other hand, more than half of the patients undertake physiotherapy. While nearly half of the patients usually use antiseptic solutions, a third of them practice wound dressing (Table 2).

\section{KNOWLEDGE OF THE RESPONDENTS}

The knowledge scores of the respondents were poor for $276(65.1 \%)$ and good for 148 $(34.9 \%)$. The level of knowledge significantly varied between age groups $(\mathrm{p}<0.01)$. As the age of the respondents increases, their knowledge score decreases. Younger age groups $(\leq 33$ years) had significantly higher knowledge scores, while older age groups ( $>53$ years) had the lowest knowledge scores. Knowledge scores were also significantly different between male and female. While $43.2 \%$ males had good knowledge about leprosy, only $24.5 \%$ of females had good knowledge $(\mathrm{P}=0 \cdot 000)$. Regarding marital status, single respondents had better leprosy knowledge than the other groups $(\mathrm{p}=0.003)$. Only $4.5 \%$ of respondents who do not read and write had good knowledge scores. On the other hand, $63.8 \%$ of respondents who are educated to secondary school or above had good knowledge of leprosy, compared to the other groups $(\mathrm{p}<0 \cdot 01)$. Unmarried people had better knowledge than people of other marital status $(\mathrm{p}=0.003)$. Poor knowledge is a characteristic of people who earn less than 150 ETB/month ( $\sim \$ 5 /$ month). Access to media and having awareness of leprosy was associated

Table 2. Self-care practice of leprosy patients, ALERT Hospital

\begin{tabular}{lrr}
\hline Characteristics & Number $(\mathrm{N})$ & Percent $(\%)$ \\
\hline Use paraffin wax lubricant as prescribed & & \\
$\quad$ No & 381 & $89 \cdot 9$ \\
$\quad$ Yes & 43 & $10 \cdot 1$ \\
Exercise trimming of the wound edge & 325 & $76 \cdot 7$ \\
$\quad$ No & 96 & $22 \cdot 6$ \\
yes & 3 & $0 \cdot 7$ \\
Occasionally & 345 & $81 \cdot 4$ \\
Believe soaking is important & 79 & $18 \cdot 6$ \\
$\quad$ No & & \\
Yes & 198 & $46 \cdot 7$ \\
Perform physiotherapy & 226 & $53 \cdot 3$ \\
$\quad$ No & 279 & $65 \cdot 8$ \\
Yes & 145 & $34 \cdot 2$ \\
Make wound dressing & & $93 \cdot 2$ \\
$\quad$ No & 395 & $6 \cdot 8$ \\
Yes & 29 & $52 \cdot 6$ \\
Clean the wound & & $46 \cdot 5$ \\
$\quad$ No & 223 & 0.9 \\
Yes & 197 & \\
$\quad$ No antiseptic solution usually & 4 & \\
$\quad$ Yes & & \\
Occasionally & & \\
\hline
\end{tabular}

Total sample size $=424$ respondents. 
Table 3. Knowledge level of leprosy patients towards the disease by socio-demographic characteristics and income status at ALERT Hospital

\begin{tabular}{|c|c|c|c|c|}
\hline Variable & Poor Knowledge & Good knowledge & Total (N) & Significance test* \\
\hline Age (years) & $\mathrm{N}(\%)$ & $\mathrm{N}(\%)$ & & \\
\hline $14-23$ & $15(37 \cdot 5)$ & $25(62 \cdot 5)$ & 40 & $X^{2}=22 \cdot 37$ \\
\hline $24-33$ & $26(53 \cdot 1)$ & $23(46 \cdot 9)$ & 49 & $\mathrm{p}$ value $<0.01$ \\
\hline $34-43$ & $42(62 \cdot 7)$ & $25(37 \cdot 3)$ & 67 & \\
\hline $44-53$ & $70(71.4)$ & $28(28 \cdot 6)$ & 98 & \\
\hline$>53$ & $123(72 \cdot 4)$ & $47(27 \cdot 6)$ & 170 & \\
\hline Total & $276(65 \cdot 1)$ & $148(34.9)$ & 424 & \\
\hline \multicolumn{5}{|l|}{ Sex } \\
\hline Male & $134(56 \cdot 8)$ & $102(43 \cdot 2)$ & 236 & $X^{2}=16 \cdot 195$ \\
\hline Female & $142(75 \cdot 5)$ & $47(24 \cdot 5)$ & 188 & $\mathrm{p}$ value $<0.01$ \\
\hline Total & $276(65 \cdot 1)$ & $148(34.9)$ & 424 & \\
\hline \multicolumn{5}{|l|}{ Marital status } \\
\hline Single & $51(51 \cdot 5)$ & $48(48 \cdot 5)$ & 99 & $X^{2}=15.932$ \\
\hline Married & $160(70 \cdot 8)$ & $66(29.9)$ & 226 & $\mathrm{p}$ value $=0.003$ \\
\hline Divorced & $28(53.8)$ & $24(46 \cdot 2)$ & 52 & \\
\hline Separated & $6(66 \cdot 6)$ & $3(33.4)$ & 9 & \\
\hline Widowed & $31(81 \cdot 6)$ & $7(18 \cdot 4)$ & 38 & \\
\hline Total & $276(65 \cdot 1)$ & $148(34.9)$ & 424 & \\
\hline \multicolumn{5}{|l|}{ Educational status } \\
\hline Illiterate & $170(95 \cdot 5)$ & $08(4 \cdot 5)$ & 178 & $X^{2}=79 \cdot 185$ \\
\hline Read and write & $28(48 \cdot 3)$ & $30(51 \cdot 7)$ & 58 & $\mathrm{p}$ value $<0.01$ \\
\hline Primary & $44(46 \cdot 8)$ & $50(53 \cdot 2)$ & 94 & \\
\hline Secondary $\&$ above & $34(36 \cdot 2)$ & $60(63.80)$ & 94 & \\
\hline Total & $276(65 \cdot 1)$ & $148(34.9)$ & 424 & \\
\hline \multicolumn{5}{|l|}{ Income (ETB) } \\
\hline $0-150$ & $95(81.9)$ & $21(18 \cdot 1)$ & 116 & $X^{2}=15.05$ \\
\hline $151-450$ & $84(71 \cdot 1)$ & $25(22.9)$ & 109 & $\mathrm{p}$ value $=0.005$ \\
\hline $451-600$ & $49(67 \cdot 1)$ & $24(32.9)$ & 73 & \\
\hline $601-1000$ & $38(47 \cdot 5)$ & $42(52 \cdot 5)$ & 80 & \\
\hline$>3000$ & $10(21 \cdot 7)$ & $36(78 \cdot 3)$ & 46 & \\
\hline Total & $276(65 \cdot 1)$ & $148(34 \cdot 9)$ & 424 & \\
\hline \multicolumn{5}{|l|}{ Religion } \\
\hline Orthodox & $227(81 \cdot 5)$ & $113(18 \cdot 5)$ & 340 & $X^{2}=3 \cdot 148$ \\
\hline Muslim & $29(60 \cdot 4)$ & $19(39 \cdot 6)$ & 48 & $\mathrm{p}$ value $=0.533$ \\
\hline Protestant & $17(58 \cdot 6)$ & $12(41 \cdot 4)$ & 29 & \\
\hline Catholic & $2(50.0)$ & $2(50 \cdot 0)$ & 4 & \\
\hline Others & $1(33 \cdot 3)$ & $2(66 \cdot 7)$ & 3 & \\
\hline Total & $276(65 \cdot 1)$ & $148(34.9)$ & 424 & \\
\hline \multicolumn{5}{|l|}{ Ethnicity } \\
\hline Amhara & $186(67 \cdot 1)$ & $91(32 \cdot 9)$ & 277 & $X^{2}=8.596$ \\
\hline Oromo & $51(65.4)$ & $27(34 \cdot 6)$ & 78 & $\mathrm{p}$ value $=0.072$ \\
\hline Tigrae & $7(43 \cdot 8)$ & $9(56 \cdot 2)$ & 16 & \\
\hline Guragie & $24(70 \cdot 6)$ & $10(29.4)$ & 34 & \\
\hline Somale & $8(42 \cdot 1)$ & $11(57.9)$ & 19 & \\
\hline Total & $276(65 \cdot 1)$ & $148(34.9)$ & 148 & \\
\hline \multicolumn{5}{|l|}{ Access to media } \\
\hline Yes & $171(60 \cdot 4)$ & $112(39 \cdot 6)$ & 283 & $X^{2}=5.908$ \\
\hline No & $105(74.5)$ & $36(25 \cdot 5)$ & 141 & $\mathrm{p}$ value $=0.015$ \\
\hline Total & $276(65 \cdot 1)$ & $148(34.9)$ & 424 & \\
\hline \multicolumn{5}{|l|}{ Awareness of leprosy } \\
\hline Yes & $178(62.9)$ & $105(37 \cdot 1)$ & 283 & $X^{2}=1.808$ \\
\hline No & $98(69 \cdot 5)$ & $43(30 \cdot 1)$ & 141 & $\mathrm{p}$ value $=0.179$ \\
\hline Total & $276(65 \cdot 1)$ & $148(34.9)$ & 424 & \\
\hline \multicolumn{5}{|c|}{ Confident that they are properly treated } \\
\hline Yes & $215(62 \cdot 2)$ & $125(36 \cdot 8)$ & 340 & $X^{2}=4.727$ \\
\hline No & $61(72 \cdot 6)$ & $23(527 \cdot 4)$ & 84 & $\mathrm{p}$ value $=0.030$ \\
\hline Total & $276(65 \cdot 1)$ & $148(34.9)$ & 424 & \\
\hline \multicolumn{5}{|c|}{ Received health education } \\
\hline Yes & $228(64 \cdot 4)$ & $126(35 \cdot 6)$ & 354 & $X^{2}=0.446$ \\
\hline No & $48(68 \cdot 6)$ & $22(31.4)$ & 70 & $\mathrm{p}$ value $=0.504$ \\
\hline Total & $276(65 \cdot 1)$ & $148(34.9)$ & 424 & \\
\hline
\end{tabular}

$*$ P-value statistically significant at $\alpha=0.05 ; \mathrm{X}^{2}=$ Chi-square; ETB $=$ Ethiopian Birr. 
with having good knowledge. On the other hand, there was no statistically significant difference between those who received health education and those who did not receive health education ( $\mathrm{p}>0.05)$. Similarly, religion and ethnicity had no impact on the level of the knowledge of the respondents (Table 3 ).

\section{SELF-CARE PRACTICE}

The level of self-care practice was assessed among 424 leprosy patients. Respondents in the age range of 24-33 years had the highest level of self-care practice $(44.9 \%)$ followed by the age group 14-23 years ( $\mathrm{p}=0.002)$. The assessment of self-care practice showed that as age increases, the level of self-care practice decreases, indicating that age is an important factor in leprosy self-care practice. Patients who had previous disability due to leprosy had a higher level of self-care practice $(62.5 \%)$ than those who had no previous disability due to leprosy. Similarly, patients who had good knowledge (62.8\%) about leprosy had better self-care practice than those who had poor knowledge $(\mathrm{p}=0.038)$. With regard to the income status of the respondents, as income increases, the level of self-care practice increases (Table 4).

Although males had more leprosy knowledge compared to females, the level of self-care practice for leprosy was not significantly different between males and females. Similarly, educational and marital status of the respondents was not associated with leprosy self-care practice $(\mathrm{p}>0.05)$. Interestingly, leprosy self-care practice was not significantly different between those who received health education and those who did not receive health education (Table 4).

\section{Discussion}

As the study reveals, nine in 10 people earn less than $\$ 1 /$ day which indicates the liklihood of an association between leprosy and poverty in Ethiopia. Although it is very difficult to demonstrate conclusively, several epidemiological studies have consistently reported a strong association between leprosy and poverty at community and household level, for example, in Indonesia, ${ }^{13}$ in Bangladesh, ${ }^{14}$ in Malawi ${ }^{15}$ and in India. ${ }^{16}$

Generally, it was found that leprosy patients had poor knowledge about the disease and poor self-care practice. Over the past 2 decades the leprosy program has initiated the integration of leprosy control services into the general health care services in Ethiopia. ${ }^{5}$ However, it has been reported that integration has meant that patients are seen by general health workers during outpatient visits rather than by specialized leprosy personnel, which could lead to misdiagnosis and incorrect treatment. ${ }^{5}$ It has been a concern that integrated services give inadequate attention to activities such as prevention of disabilities and rehabilitation. $^{17}$

In leprosy, self-care is the most important type of self-management, whereby leprosy patients need to change their behavior to adapt to the irreversible impairment due to the disease. $^{3}$ Although limited information is available on the effectiveness of self-care, it has been reported that self-care practice, particularly participation in self-care groups, improves understanding of self-care. Self-care practice helps patients to reduce the number of ulcers, improve their physical condition and increase self-confidence. ${ }^{3}$ However, the effectiveness of self-care practice can be compromised by poor knowledge and perception of the disease. In our study we found that poor self-care practice was associated with older age, female sex, married status, lower educational status, lower income and less access to media. 
Table 4. Self-care practice of leprosy patients at ALERT Hospital

\begin{tabular}{|c|c|c|c|c|}
\hline \multirow[b]{2}{*}{ Variable } & \multicolumn{2}{|c|}{ Self-care practice } & \multirow[b]{2}{*}{ Total Number $(\mathrm{N})$} & \multirow[b]{2}{*}{ Significance level * } \\
\hline & Poor & Good & & \\
\hline Age (years) & $\mathrm{N}(\%)$ & $\mathrm{N}(\%)$ & & \\
\hline $14-23$ & $30(75 \cdot 0)$ & $10(25 \cdot 0)$ & 40 & $X^{2}=17 \cdot 001$ \\
\hline $24-33$ & $27(55 \cdot 1)$ & $22(44.9)$ & 49 & $\mathrm{p}$ value $=0.002$ \\
\hline $34-43$ & $52(77 \cdot 6)$ & $15(22 \cdot 4)$ & 67 & \\
\hline $44-53$ & $79(80 \cdot 6)$ & $19(19.4)$ & 98 & \\
\hline$>53$ & $140(82 \cdot 4)$ & $30(17 \cdot 6)$ & 170 & \\
\hline Total & $328(77.4)$ & $96(22 \cdot 6)$ & 424 & \\
\hline \multicolumn{5}{|l|}{ Sex } \\
\hline Male & $50(21 \cdot 2)$ & $186(78 \cdot 8)$ & 236 & $X^{2}=0.643$ \\
\hline Female & $46(25 \cdot 5)$ & $142(74 \cdot 5)$ & 188 & $\mathrm{p}$ value $=0.422$ \\
\hline Total & $96(22.6)$ & $328(77.4)$ & 424 & \\
\hline \multicolumn{5}{|c|}{ Previous disability due to leprosy } \\
\hline Yes & $123(37 \cdot 5)$ & $205(62 \cdot 5)$ & 328 & $X^{2}=49 \cdot 241$ \\
\hline No & $75(78 \cdot 1)$ & $21(21.9)$ & 96 & $\mathrm{p}$ value $<0.01$ \\
\hline Total & $198(46 \cdot 7)$ & $226(53 \cdot 3)$ & 424 & \\
\hline \multicolumn{5}{|l|}{ Knowledge of leprosy } \\
\hline Poor knowledge & $204(73.9)$ & $72(26 \cdot 1)$ & 276 & $X^{2}=4 \cdot 291$ \\
\hline Good knowledge & $55(37 \cdot 2)$ & $93(62 \cdot 8)$ & 148 & $\mathrm{p}$ value $=0.038$ \\
\hline Total & $259(61 \cdot 1)$ & $165(38.9)$ & 424 & \\
\hline \multicolumn{5}{|l|}{ Educational status } \\
\hline Illiterate & $140(78 \cdot 7)$ & $38(21 \cdot 3)$ & 178 & $X^{2}=5.069$ \\
\hline Read and write & $48(82 \cdot 8)$ & $10(17 \cdot 2)$ & 58 & $\mathrm{p}$ value $=0.167$ \\
\hline Primary & $75(79 \cdot 8)$ & $19(20 \cdot 2)$ & 94 & \\
\hline Secondary and above & $65(69 \cdot 1)$ & $29(30 \cdot 9)$ & 94 & \\
\hline Total & $328(77 \cdot 4)$ & $96(22 \cdot 6)$ & 424 & \\
\hline \multicolumn{5}{|l|}{ Income (ETB) } \\
\hline $0-150$ & $97(83.6)$ & $19(16 \cdot 4)$ & 116 & $X^{2}=10 \cdot 853$ \\
\hline $151-450$ & $90(82.6)$ & $19(17.4)$ & 109 & $\mathrm{p}$ value $=0.028$ \\
\hline $451-600$ & $59(80 \cdot 8)$ & $14(19 \cdot 2)$ & 73 & \\
\hline $601-1000$ & $55(68.8)$ & $25(31 \cdot 3)$ & 80 & \\
\hline$>1000$ & $27(58.7)$ & $19(41 \cdot 3)$ & 46 & \\
\hline Total & $328(77 \cdot 4)$ & $96(22 \cdot 6)$ & 424 & \\
\hline \multicolumn{5}{|l|}{ Marital status } \\
\hline Single & $72(72 \cdot 7)$ & $27(27 \cdot 3)$ & 99 & $X^{2}=4.537$ \\
\hline Married & $173(76 \cdot 5)$ & $53(23 \cdot 5)$ & 226 & $\mathrm{p}$ value $=0.338$ \\
\hline Divorced & $45(86 \cdot 5$ & $7(13 \cdot 5)$ & 52 & \\
\hline Widowed/widower & $8(88.9)$ & $1(11 \cdot 1)$ & 9 & \\
\hline Separated & $30(78.9)$ & $8(21 \cdot 1)$ & 38 & \\
\hline Total & $328(77.4)$ & $96(22.6)$ & 424 & \\
\hline \multicolumn{5}{|l|}{ Received Health Education } \\
\hline Yes & $277(78 \cdot 2)$ & $77(21 \cdot 6)$ & 354 & $X^{2}=0 \cdot 970$ \\
\hline No & $51(72 \cdot 9)$ & $19(27 \cdot 1)$ & 70 & $\mathrm{p}$ value $=0.325$ \\
\hline Total & $328(77.4)$ & $96(22 \cdot 6)$ & 424 & \\
\hline
\end{tabular}

$* \mathrm{P}$-value statistically significant at $\alpha=0.05 ; \mathrm{X}^{2}=$ Chi-square; ETB $=$ Ethiopian Birr.

Younger age was significantly associated with better leprosy knowledge and self-care practice (Tables 2 and 3). Patients in the age range of 14-23 years had significantly higher knowledge and good self-care practice compared to the other age groups. This could be due to the fact that people in this age group are more likely to take care of themselves as they are in the peer-forming age group. Several studies have reported that leprosy influences marriage and sexual relationships in several countries, such as Nepal, India, Bangladesh 
and Brazil. ${ }^{18,19}$ In our study, we found that females had poor leprosy knowledge and poor self-care practice compared to males. As in many developing countries, women in Ethiopia play a subordinate, submissive and more conservative gender role in seeking health care particularly in poverty stricken rural and remote areas of the country. ${ }^{20}$ Societal stigma, women's dependence and low status, self-stigmatizing attitudes, and the gender insensitivity of leprosy services are reported as barriers faced by women. ${ }^{21}$ Hence, more work is yet being to be done by health care professionals and society in general to tackle these barriers in Ethiopia, where leprosy remains endemic.

Being single is associated with relatively improved self-care and having good comparative knowledge of leprosy, compared to people of other marital status. This could be due to the fact that singles are more concerned about their future relationships and want to recover from leprosy as quickly as possible. Patients with poor education and those who have no access to any form of media had less knowledge of leprosy and had poor self-care practice. Several studies have reported that educated leprosy patients have good leprosy knowledge and leprosy self-care practice compared to uneducated patients. ${ }^{22-24}$ Hence, leprosy education and rehabilitation programs may need adult literacy programs, combined with more innovative focused approaches to suit various target audiences that can impact knowledge, attitudes and self-care practice better.

In conclusion, this study has identified that the majority of leprosy patients $(65 \%)$ have poor knowledge and poor leprosy self-care practices in spite of the fact that leprosy treatment, disability prevention and rehabilitation programs have been run in the country under the general public health care service for decades. The leprosy service program should re-visit its strategy and mode of delivery to improve the leprosy knowledge and leprosy self-care practices of patients.

\section{Author contribution}

EN, LG, KB and TH were involved in the conceptualization of the research hypothesis. LG and $\mathrm{KB}$ developed the proposal. EN and $\mathrm{TH}$ revised the research proposal. EN and $\mathrm{TH}$ validated the questionnaire and the method. LS and KB administered the research. EN and LG analyzed the data. EN drafted the manuscript. All authors revised and edited the manuscript.

\section{References}

1 WHO. Leprosy. Global situation. Wkly Epidemiol Rec, 2002; 77: 1-8.

2 WHO. Global leprosy update: accelerating reduction of disease burden No 35. WHO, 2017; 92: 501-520.

3 Bruin DW, Dijkkamp E, Post E, Van Brakel WH. Combining peer-led self-care interventions for people affected by leprosy or diabetes in leprosy-endemic countries. Lepr Rev, 2013; 84: 266-282.

4 Deepak S, Paulo Estivar H, Carole B. Self-care groups of leprosy-affected people in Mozambique. Lepr Rev, 2013; 84: 283-291.

5 Abeje T, Negera E, Kebede E et al. Performance of general health workers in leprosy control activities at public health facilities in Amhara and Oromia States, Ethiopia. BMC Health Serv Res, 2016; 16: 1-7.

${ }^{6}$ Feenstra P, Visschedijk J. Leprosy control through general health services-revisiting the concept of integration. Lepr Rev, 2002; 73: 111-122.

7 de Souza IA, Ayres JA, Meneguin S, Spagnolo RS. Hansen's disease patients' perception of self-care from the complexity perspective. Esc Anna Nery, 2014; 18: 510-514.

8 Tsutsumi A, Izutsu T, Islam MDA et al. Depressive status of leprosy patients in Bangladesh: association with selfperception of stigma. Lepr Rev, 2004; 75: 57-66. 
9 Augustine V, Longmore Miram, Ebenezer M, Richard J. Effectiveness of Social Skills Training for reduction of self-perceived Stigma in Leprosy Patients in rural India - a preliminary study. Lepr Rev, 2012; 83: 80-92.

${ }^{10}$ Susanto T, Dewi EI, Rahmawati I. The experiences of people affected by leprosy who participated in self-care groups in the community: A qualitative study in Indonesia. Lepr Rev, 2017; 88: 543-553.

11 Tabah EN, Nsagha DS, Bissek A-CZ-K et al. Community knowledge, perceptions and attitudes regarding leprosy in rural Cameroon: The case of Ekondotiti and Mbonge health districts in the South-west Region. PLOS Negl Trop Dis, 2018; 12: 1-17.

12 Mengistu K, Mohammed A, Timotios G et al. Knowledge and attitude of health professionals in relation to the integration of leprosycontrol into the general health service in Ethiopia. International Journal of Leprosy, 2000; 68: $299-304$.

13 Oktaria S, Hurif NS, Naim W et al. Dietary diversity and poverty as risk factors for leprosy in Indonesia: A casecontrol study. PLOS Negl Trop Dis, 2018; 12: 1-15.

${ }^{14}$ Feenstra SG, Nahar Q, Pahan D et al. Recent Food Shortage Is Associated with Leprosy Disease in Bangladesh: A Case-Control Study. PLoS Negl Trop Dis, 2011; 5: 1-7.

15 Roe C, May LS. A case of leprosy in Malawi. Making the final push towards eradication: a clinical and public health perspective. Infect Dis Poverty, 2016; 1: 1-5.

${ }^{16}$ Grantz KH, Chabaari W, Samuel RK et al. Spatial distribution of leprosy in India: an ecological study. Infect Dis Poverty, 2018; 7: 1-9.

${ }^{17}$ Deepak S, Hansine PE, Braccini C. Self-care groups of leprosy-affected people in Mozambique. Lepr Rev, 2013; 84: $283-291$.

${ }^{18}$ Nopparat S, Parinya J, Kunlanat M. Self-care Behaviors in a High Risk Group for Leprosy of Thambol Landokmai, Muang District, Kamphaengphet Province. Health and the Environment Journal, 2014; 5: 97-109.

19 Noordende AT, van Brakel WH, Banstola N, Dhakal PK. The Impact of Leprosy on Marital Relationships and Sexual Health among Married Women in Eastern Nepal. J Trop Med, 2016: 1-9.

${ }^{20}$ Mebratie AD, Van de Poel E, Yilma Z et al. Healthcare-seeking behaviour in rural Ethiopia: evidence from clinical vignettes. BMJ Open, 2014; 4: 1-12.

${ }^{21}$ Price VG. Factors preventing early case detection for women affected by leprosy: a review of the literature. Glob Health Action, 2017; 10: 1-10.

${ }^{22}$ Barkataki P, Kumar S, Rao PS. Knowledge of and attitudes to leprosy among patients and community members: a comparative study in Uttar Pradesh, India. Lepr Rev, 2006; 77: 62-68.

${ }^{23}$ Adhikari B, Kaehler N, Chapman RS et al. Factors Affecting Perceived Stigma in Leprosy Affected Persons in Western Nepal. PLOS Negl Trop Dis, 2014; 8: 1-8.

${ }^{24}$ Lira KB, Leite JJG, Castelo Branco de Souza Collares Maia D et al. Knowledge of the patients regarding leprosy and adherence to treatment. Braz J Infect Dis, 2012; 16: 472-475. 